\title{
EL ESCULTOR FRANCISCO ELÍAS VALLEJO (1782-1858). ESTADO DE LA CUESTIÓN Y NUEVAS APORTACIONES
}

\author{
Myriam FerReira FernáNDEZ ${ }^{1}$ \\ Universidad Internacional de La Rioja
}

\begin{abstract}
Francisco Elías Vallejo fue un destacado escultor español de la primera mitad del siglo XIX. Formado en la Real Academia de Bellas Artes de San Fernando, desarrolló una larga carrera como Escultor de Cámara del rey y como profesor de la Real Academia, donde fue Director de Escultura y Director General en dos ocasiones.

En este artículo se trata de recoger la información sobre él publicada hasta el momento y completarla con datos extraídos de archivos y prensa de la época. Con ello, se busca completar las lagunas existentes en su biografía, como su formación antes de su llegada a Madrid. Además, se ordena y sintetiza la información sobre su actividad artística, recogiendo un listado lo más completo posible de sus obras y la información existente sobre ellas, que pueda servir de base para posteriores estudios.

Palabras clave: Francisco Elías Vallejo; escultura; Real Academia de Bellas Artes de San Fernando; Escultores de Cámara; neoclasicismo; romanticismo; escultura pública; retratos; escultura religiosa.
\end{abstract}

\section{THE SCULPTOR FRANCISCO ELÍAS VALLEJO (1782-1858). STATE OF THE ART AND NEW CONTRIBUTIONS}

Francisco Elías Vallejo was a prominent sculptor who worked in the first half of the XIXth century. He studied at the Royal Academy of Fine Arts of San Fernando and developed a long career as a Court Sculptor and as a teacher at the Royal Academy, where he was Director of Sculpture and, twice, General Director.

In this paper, information from publications about him is recollected and completed with data extracted from archives and historic press. The objective is to complete the lack of information about his life, for instance, his education in his village before his trip to Madrid. Furthermore, information about his artist activity is ranked and summarized to make a list of their works as complete as possible, so that subsequent studies can base on it.

Key words: Francisco Elías Vallejo; sculpture; Royal Academy of Fine Arts of San Fernando; Court Sculptors; Neoclassicism; Romanticism; public sculpture; portraits; religious sculpture.

Cómo citar este artículo / Citation: Ferreira Fernández, Myriam (2017): "El escultor Francisco Elías Vallejo (1782-1858). Estado de la cuestión y nuevas aportaciones". En: Archivo Español de Arte, vol. 90, núm. 359, Madrid, pp. 261-274. doi: 10.3989/aearte.2017.17

\section{Introducción}

Francisco Elías Vallejo es uno de los escultores españoles más destacados de la primera mitad del siglo XIX. Su figura está ligada tanto a la Real Academia de Bellas Artes de San Fernando, de la que fue profesor y Director General, como a la escultura pública cortesana, ya que como

1 myriam.ferreira@unir.net / ORCID iD: http://orcid.org/0000-0002-5782-5033 
Escultor de Cámara participó en algunos de los monumentos públicos más destacados de su época.

$\mathrm{Su}$ trascendencia hizo que fuera muy pronto estudiado por historiadores del arte, incluso contemporáneos suyos ${ }^{2}$. Tras su muerte, su figura fue recogida por Sala en 1862, aunque con algunos errores ${ }^{3}$ y Ossorio en 1883, quien ofrecía mayor información sobre su carrera en la Real Academia y las obras realizadas por él, aunque también incluía alguna equivocación ${ }^{4}$. En 1903 Silverio Domínguez publicaba un opúsculo, el más amplio dedicado hasta el momento a Elías, donde recogía incluso testimonios directos de personas que le conocieron. Domínguez aportaba datos sobre su niñez, le atribuía obras conservadas en La Rioja y se interesaba por aspectos familiares, aunque el tono de la obra se caracteriza más por su entusiasmo que por su rigor $^{5}$. En obras posteriores, como la Enciclopedia Espasa publicada en 1908 o la obra de Serrano Fatigati de 1912, se recogía su figura, pero repitiendo los datos de otros autores ${ }^{6}$. Fue en 1951 cuando Pardo Canalis publicó Escultores del siglo XIX, el estudio mejor documentado hasta el momento sobre Elías. Pardo corrigió errores de otros autores, como la fecha de nacimiento, títulos de obras, etc., reconstruyó toda su trayectoria tanto en la Academia como en el ámbito cortesano y transcribió documentación relevante sobre el $\operatorname{artista}^{7}$. A partir de ese momento, se han ido haciendo menciones a Elías en publicaciones variadas, pudiendo destacarse las de Leticia Azcue, quien analiza las obras conservadas de Elías en la Real Academia de San Fernando, y las de Ramírez Martínez y Cerrillo, que estudian la figura de Elías desde el ámbito riojano ${ }^{8}$.

El objetivo de este artículo es sintetizar estas aportaciones para facilitar el conocimiento de la figura de este escultor, incluyendo algunos datos novedosos que corrijan y completen el perfil de este artista. Asimismo, se han recogido todas sus obras conocidas, con la bibliografía sobre ellas, aunque sin entrar en un análisis detallado que excedería la extensión de este trabajo.

\section{Datos biográficos}

Francisco Elías Vallejo nació en Soto en Cameros el 4 de octubre de 1782, hijo de Nicolás de Elías Rodríguez y de Manuela Vallejo Rubio?.

$\mathrm{Su}$ familia tenía un origen muy humilde. Domínguez suponía que sus padres podrían haber trabajado en alguna de las numerosas fábricas de paños de Soto, pero no encontró testimonios que corroboraran su hipótesis ${ }^{10}$. Podemos aportar que sus abuelos, según el Catastro de Ensenada, realizado hacia 1754, se dedicaban a oficios relacionados con la ganadería, algo muy habitual en la zona de Cameros: su abuelo paterno, Juan de Elías, era cardador, además de tener, como única cabeza de ganado, un cerdo para criar, y su abuelo materno, Juan Vallejo, era arriero y

\footnotetext{
2 Su yerno, Agustín Subirat, indicaba en 1859 que ya existía una biografía de Elías, obra de Braulio Sebastián Castellanos, titulada Biografias de artistas españoles, pero que no hemos podido localizar (Archivo de la Real Academia de Bellas Artes de San Fernando (ARASF), Fallecimientos y noticias biográficas, 1-47-2: s.f.). Asimismo, Ossorio cita como fuente un artículo sobre Elías publicado en la revista Las Bellas Artes, y que tampoco hemos localizado (Ossorio, 1883: 184).

${ }^{3}$ Por ejemplo, identificaba el río esculpido para el monumento de Felipe IV como el Tajo, aunque es el Manzanares, y proponía como fecha de nacimiento 1772, en vez de 1782 (Sala, 1862: 367).

${ }_{4}$ Proponía como fecha de nacimiento 1783, en vez de 1782 (Ossorio, 1883: 184-185).

5 Domínguez, 1903.

${ }^{6}$ Espasa, 1908: 764. Serrano, 1912: 295-296.

7 Pardo, 1951: 113-120.

8 Gómez, 1993: 54-56. Azcue, 1994: 390-391. Ramírez, 1998: 36-38. Cerrillo, 2005: 135-139. Calvo Torre, 2008 : 69. Ramírez, 2011: 151-153.

9 Archivo Histórico Diocesano de Logroño (AHDL), Soto en Cameros, Bautizados 6 (1740-1786): 411 v. Pardo, 1951: 113.

10 Domínguez, 1903: 55.
} 
tenía un terreno para el cultivo de secano ${ }^{11}$. Por su parte, la prensa de la época, que se hacía eco de los orígenes humildes de Elías, indicaba escuetamente que Elías Vallejo era hijo de un agricultor $^{12}$.

Aún desconocemos qué movió a Elías a formarse como artista, aunque podemos completar la información conocida hasta ahora. Domínguez indicaba que el joven se había iniciado en el arte de una manera autodidacta, "sin guía ni dirección, sin modelos ni estímulos", debido a que tenía una habilidad connatural, ya que "en sus ratos de ocio y de recreo [realizaba] figuras en el barro y la madera", de modo que en el pueblo "de boca en boca corría el comentario diario acerca de la habilidad del chico"13.

Sin embargo, lo cierto es que el propio Elías afirmaba en 1814 que "tubo los principios de dibujo en el pueblo de su naturaleza"14. Hasta ahora se desconocía el nombre de su maestro, pero se ha localizado en un periódico de la época: se trataba de Bernabé Romero, sacerdote, pintor y escultor ${ }^{15}$. De Romero, nacido en Soto en Cameros en torno a 1749, no conocemos muchos datos y no tenemos constancia de ninguna obra realizada por él. Sí que podemos indicar que tenía un carácter liberal, hasta el punto de que durante la Guerra de la Independencia fue propuesto por el obispo Aguiriano para representar a La Rioja en las Cortes Generales ${ }^{16}$. Es de suponer que Romero sería el sacerdote que, según Domínguez, se ofreció a pagar a Elías una manutención de 3 reales diarios para que pudiera trasladarse a estudiar a Madrid ${ }^{17}$.

El 8 de septiembre de 1802, Elías solicitó ser admitido en la Real Academia de Bellas Artes de San Fernando. En su solicitud, indicaba " $\mathrm{q}[\mathrm{u}] \mathrm{e}$ por la singular inclinación $\mathrm{q}[\mathrm{u}] \mathrm{e}$ profesa a la noble arte de la escultura ha venido a esta Corte a exercitarse en ella" ${ }^{18}$. El 15 de septiembre fue admitido en la Academia, siendo inscrito en la sala de principios ${ }^{19}$.

Simultáneamente, y nuevamente según el propio Elías, recibió una formación práctica como escultor junto al escultor aragonés Juan Adán ${ }^{20}$. Previamente, según Ramírez, había estado en el taller del escultor, también aragonés, Pascual Cortés ${ }^{21}$.

$\mathrm{Su}$ asistencia a las salas de la Academia ha quedado reflejada en las actas de esta institución: seis meses después de matricularse, el 1 de mayo de 1803, pasó a la sala de cabezas; otros seis meses después, el 6 de noviembre de 1803, pasó a la sala de figuras y apenas cuatro meses después, el 4 de marzo de 1804, pasó a la sala del yeso. En esta sala permaneció algo más de tiempo, casi tres años, hasta que el 1 de febrero de 1807 pasó a la sala del natural22. Durante este tiempo, ganó "tres [premios] extraordinarios, los dos en el modelo del natural y otro en el del antiguo" 23 .

En 1808, en plena Guerra de la Independencia, ganó el segundo premio de la primera clase en los Premios Generales de la Real Academia. De las dos pruebas que presentó, el relieve de pensado, que representaba a Hernán Cortés mandando quemar las naves, se conservó en la Aca-

11 Archivo Histórico Provincial de La Rioja (AHPLR), Catastro de Ensenada, Soto en Cameros, Libro de lo personal de seglares, vol. 658, n. ${ }^{\circ}$ 264: 55 v.; n. ${ }^{\circ}$ 242: 31 r.; Libro de lo raíz de seglares, vol. 661, n. ${ }^{\circ}$ 164: 1042 r.; vol. 660, n. ${ }^{\circ} 420: 844 \mathrm{r}$.

12 "Origen de algunos hombres célebres". En: Boletín oficial del Gran Oriente de España, 1-8-1873:13.

13 Domínguez, 1903: 56

14 ARASF, Escultores, 5-173-2: s/f.

15 "Cameros". En: La Ilustración. Periódico Universal, Madrid, 27-4-1850:133. En ese periódico, en una lista de cameranos ilustres, se citaba "al presbítero D. Bernabé Romero, predicador famoso, pintor y escultor de la provincia de Soria, y maestro del expresado Sr. Elías Vallejo".

16 Lecuona, 1954: 452.

17 Domínguez, 1903: 57.

18 Archivo de la Facultad de Bellas Artes de la Universidad Complutense de Madrid, Solicitudes de admisión en la Real Academia de San Fernando, 32 (1802): s/f.

19 ARASF, Libro de Matrícula (1799-1802): $43 \mathrm{v}$.

${ }^{20}$ ARASF, Escultores, 5-173-2 (1800-1818): s/f. Pardo, 1951: 114. Cerrillo, 2005: 136.

21 Ramírez, 2011: 151.

22 ARASF, Actas, 3-87 (1803-1818): 21, 54, 73, 295. Pardo, 1951: 114.

23 ARASF, Escultores, 5-173-2, s/f. 
demia, pero no así el relieve de repente, que representaba El rey Don Enrique conduciendo el palafrén de su hermana Doña Isabel por las calles de Segovia ${ }^{24}$.

El 13 de abril de 1814, al poco de terminar la guerra, contrajo matrimonio con Juliana Burgos Montalvo, una joven madrileña ${ }^{25}$. No debía de ser tampoco de familia pudiente ya que ningún de los dos aportó bienes al matrimonio ${ }^{26}$.

La familia se instaló en la calle San Juan, aunque posteriormente se trasladaron a la calle Fúcar 10, principal, que sería en adelante el domicilio familiar ${ }^{27}$. Esa casa incluía un gran taller: de hecho, Elías renunció a utilizar el taller reservado al Primer Escultor de Cámara "por tener en su casa obrador más cómodo $\mathrm{p}[\mathrm{ar}] \mathrm{a}$ toda clase de obras" 28.

Francisco y Juliana tuvieron seis hijos: Francisca (n. 29/01/1815), Francisco (n. 18/07/1816), María Josefa de la Cruz (n. 14/09/1820), María de la Encarnación (n. 26/03/1821), Eloísa (n. 16/07/1822) y Josefa (n. 27/03/1824) ${ }^{29}$. De todos ellos, solo tres llegaron a la edad adulta: Francisco, María Encarnación y Eloísa.

Del que más información tenemos es de Francisco, escultor como su padre, Académico de Mérito y profesor en el Estudio de la Trinidad ${ }^{30}$. Falleció de tuberculosis el 19 de octubre de 1848, a los 32 años $^{31}$. Sobre sus hermanas, podemos añadir que María debió de casarse con Antonio de Castresana, de quien no tenemos más datos ${ }^{32}$ y que Eloísa se casó con Agustín Subirat ${ }^{33}$, probablemente de origen valenciano ${ }^{34}$ y que al parecer trabajaba como contratista de diferentes encargos arquitectónicos, como la ampliación del Matadero de Madrid o el Asilo de Niñas de las Mercedes ${ }^{35}$. Eloísa falleció el 7 de marzo de $1887^{36}$.

Hacia 1830, Elías empezó a experimentar ciertos problemas de salud, que se identifican como ataques reumáticos y debilidad cerebral. Por este motivo, fue solicitando distintos permisos para trasladarse a lugares con aguas medicinales ${ }^{37}$. También por esas mismas fechas, el 5 de febrero de 1833, Francisco y Juliana otorgaron su testamento ${ }^{38}$. La rápida sucesión de las muertes de su hijo en 1848 y de su mujer en 1857 afectaron aún más a su salud. Finalmente, Elías falleció en Madrid el 22 de septiembre de 1858 , a causa de una afección estomacal ${ }^{39}$.

\section{Actividad artística de Francisco Elías Vallejo}

La actividad artística de Elías tuvo dos ámbitos predominantes: la Real Academia de San Fernando y la actividad como Escultor de Cámara al servicio del Rey. A estos dos ámbitos se

${ }^{24}$ ARASF, Inventarios generales, 3-616 (1804-1814): 36 r.; 3-620 (1824): 91 r.; C-11126 (1829):93, 2-57-6 (1840):42 r.; 1-14-4 (1855): 14 v. Ossorio, 1883: 184-185. Pardo, 1951: 116. Azcue, 1994: 390-391. Mazón, 2001: $139-140$

25 Archivo de la Parroquia de San Sebastián (AP San Sebastián), Matrimonios 36: 102 v. Fernández, 1995: 206.

26 Archivo Histórico de Protocolos de Madrid (AHPM), Protocolos notariales, 24186: 375-378.

27 ARASF, Secretario general. Académicos. Domicilios, 5-91-4 (s. XIX): s/f; Pardo, 1951: 120 y 294.

28 Pardo, 1951: 294.

${ }^{29}$ AP San Sebastián, Bautizados 64: 64 r. y 327 r.; 65: 183 r. y 390 v.; 66: 240 r.; 67: 238 v. Fernández, 1995: 206.

30 Pardo, 1952a: 375-380.

31 AP San Sebastián, Difuntos 44: 347. Fernández, 1995: 206.

32 Elías indicaba en 1851 que tenía un yerno llamado Antonio Castresana, a quien daba permiso para cobrar su sueldo mientras él estaba ausente de permiso. ARASF, Escultores, 5-172-2 (1800-1818): s/f.

33 ARASF, Fallecimientos y noticias biográficas, 1-47-2: s.f.

34 "Noticias de España". En: El Eco del comercio, 17-12-1838: 2.

35 "Ayuntamiento de Madrid". En: Diario oficial de avisos de Madrid, 22-1-1877: 1-2. "Asilo de Nuestra Señora de las Mercedes". En: Diario oficial de avisos de Madrid, 11-3-1897: 3.

36 "Esquelas". En: La Correspondencia de España, 9-3-1887: 4.

37 Archivo General de Palacio (AGP), Exp. 16864/39, expediente 1, 6, 11 y 26. Pardo, 1951: 115 y 291.

38 Pardo, 1951: 115. AHPM, Protocolos notariales, 24186, fols. 375-378. Agulló, 2005: 100-101.

39 AP San Sebastián de Madrid, Difuntos. Pardo, 1951: 115 y 291. Fernández, 1995: 206. 
añadiría su trabajo en la Platería Martínez de Madrid y los encargos particulares recibidos, especialmente de escultura religiosa.

\section{La actividad de Francisco Elías Vallejo en la Real Academia de San Fernando}

En 1814, Elías solicitó el título de Académico de Mérito en la Real Academia de San Fernando, que le fue concedido el día 2 de octubre, tras la valoración de un relieve que representara $E l$ duelo entre el moro Albayaldos y Rodrigo Téllez Girón, y que se conserva aún en la Academia ${ }^{40}$. A partir de este nombramiento, Elías fue presentándose a distintas vacantes para ir ascendiendo en la carrera académica: así, fue nombrado Teniente Director de Escultura en 1818, Director de Escultura en 1830 y Director General de la Real Academia en 1841 y 1851. Los avatares de esta carrera académica han sido bien estudiados por los autores que han tratado sobre él ${ }^{41}$.

La actividad fundamental realizada por Elías en la Academia fue la docencia, que desempeñó siendo Teniente de Escultura en el estudio de la Calle Trinidad, dependiente de la Academia, y siendo Director de Escultura en el centro de la calle Alcalá, aunque en 1845 volvió a ser nombrado Director de los Estudios Menores de la Academia ${ }^{42}$. Su labor como profesor debió ser bien valorada, ya que algunos estudiantes aún le recordaban años después de haber abandonado la enseñanza ${ }^{43}$. Tal vez de esa época como profesor date un retrato de Elías, realizado por Carlos Luis de Ribera, conservada hoy en la Biblioteca Nacional, y que parece ser una caricatura realizada por el joven pintor a la vez que la de su propio padre ${ }^{44}$.

Además de las clases de dibujo impartidas para la Academia, Elías también desempeñó la docencia con jóvenes escultores que se formaron en su taller. El más destacado fue Francisco Pérez del Valle, que acudió al taller de Elías por recomendación del arquitecto Juan Miguel Inclán Valdés ${ }^{45}$, aunque también constan como discípulos suyos los escultores Gabriel María Pintado y Vicente Santa Coloma ${ }^{46}$, así como Ramón Subirat ${ }^{47}$.

Como académico, Elías también recibió ocasionalmente encargos de obras escultóricas. Poco antes de 1824, Elías realizó un elegante busto en mármol de la reina María Amalia Josefa de Sajonia que aun hoy se conserva en la Academia ${ }^{48}$. Domínguez opinaba que debía de ser también obra de Elías otro busto en mármol que representaba a Fernando VII, atribución recogida por Pardo Canalís aunque puesta en duda por Azcue ${ }^{49}$. La tercera escultura representaría a La reina con la Princesa de Asturias en brazos, citada por Pardo Canalís y de la que, sin embargo, no tenemos más datos actualmente ${ }^{50}$.

A estas obras habría que añadir también algunos modelos de obras que no se llegaron a realizar pero que se conservaron en la Real Academia: un modelo para un monumento que conme-

40 ARASF, Actas, 3-87 (1803-1818): 488-489; Inventarios generales, 3-620 (1824): 91 v.; C-11126 (1829): 92, 2-57-6 (1840): 42 r.; 1-14-4 (1855): 14 v. Rincón, 1909: 295. Pardo, 1951: 116. Ramírez, 1998: 36. Arias, $1999: 80$. Álvarez, 2003: 531. Cerrillo, 2005: 135.

${ }^{41}$ Pardo, 1951: 113-115. Navarrete, 1999: 61, 68, 69, 75, 152, 189, 190, 238, 349, 392, 433 (quien, por error, le apellida Elías Burgos). Cerrillo, 2005: 135-139. Ramírez, 2011: 151-152.

${ }^{42}$ Pardo, 1951: 115.

43 Araujo, 2005: 66.

44 Barcia, 1901: 573.

45 Mellado, 1848: 68. Gómez, 1993: 62.

46 Ballesteros, 1912: 518 y 589.

47 Gómez, 1993: 75.

48 ARASF, Inventarios generales, 3-620 (1824): 56 v.; C-11126 (1829): 47-48, 2-57-6 (1840): 21 r.; 1-14-4 (1855): 2 v. Ossorio, 1883: 184-185. Domínguez, 1903: 107. Pardo, 1951: 118. Azcue, 1994: 391-392; 2012: 346. Ramírez, 1998: 37-38. Arias, 1999: 80. Álvarez, 2003: 531. Cerrillo, 2005: 137. Ramírez, 2011: 153.

49 Domínguez, 1903: 107-108. Pardo, 1951: 118. Azcue, 1994: 392-393; 2012: 346. Ramírez, 1998: 38. Álvarez, 2003: 531. Cerrillo, 2005: 137. Ramírez, 2011: 153.

50 Ossorio, 1883: 184-185. Rincón, 1909: 295. Arias asegura que la reina es Isabel II (Arias, 1999: 80), mientras que Ramírez la identifica con María Cristina (Ramírez, 1998: 37; Ramírez, 2011: 152). 
morara Fernando VII jurando la Constitución Española, convocado en $1821^{51}$ y una escultura que representara a Fernando VII destinada a La Habana, en $1828^{52}$.

Otra faceta de la actividad de Elías ligada a la Real Academia fue la valoración de diferentes obras para su selección, inventario o tasación, lo cual indica una gran confianza en su criterio artístico. Las valoraciones que conocemos realizadas por Elías son las siguientes:

- Reconocimiento e inventario de las obras artísticas procedentes de los conventos suprimidos por la Desamortización de Mendizábal (1835), labor que inició en Madrid y luego solicitó continuar fuera de la Corte ${ }^{53}$.

- Valoración de vaciados en escayola de la Academia para seleccionar algunos que decoraran la fachada del Teatro Jovellanos en Gijón (1853), aunque finalmente se optó por encargar unas esculturas al artista José Gragera ${ }^{54}$.

- Valoración de la escultura Isabel II velada, realizada por el italiano Camillo Torreggiani y que Elías y José Piquer tasaron en 34.000 reales $^{55}$.

- Jurado en la primera Exposición General de Bellas Artes que sustituía a las exposiciones de los premios de la Real Academia $(1856)^{56}$.

Además, en la Real Academia coincidió con otros artistas con los que mantuvo una relación cordial. De hecho, encargó a uno de estos compañeros, el pintor Zacarías González Velázquez, la realización de un retrato, excelente, que pasó a pertenecer a su familia hasta que su hija María Encarnación lo donó a la Real Academia de San Fernando en $1900^{57}$, a cuyos fondos aún hoy pertenece.

\section{La actividad de Francisco Elías Vallejo como Escultor de Cámara}

Simultáneamente a su labor en la Real Academia de San Fernando, Elías también trató de obtener el nombramiento como Escultor de Cámara, una carrera aún más accidentada que la académica y también bien estudiada por los autores que han tratado sobre él ${ }^{58}$. El resultado de sus esfuerzos se tradujo en que fue nombrado Ayudante del Escultor de Cámara en 1816, Segundo Escultor de Cámara en 1831 y Primer Escultor de Cámara en 1836.

Estos nombramientos coincidieron con el momento en que comenzaba la empresa de monumentalizar la capital ${ }^{59}$, lo que favoreció que le fueran encargadas muchas obras y en general de gran prestigio:

- Escultura de Fernando VII en Murcia (1830). Se trataba de una imagen de tamaño mayor que el natural (aproximadamente 2.50 metros) realizada en plomo dorado e inaugurada en 1831. Su existencia fue breve: solo 6 años después, en 1837, la escultura fue destruida por los liberales murcianos, que la fundieron y usaron el plomo para fabricar balas ${ }^{60}$.

\footnotetext{
51 Pardo, 1951: 116.

52 ARASF, Actas, 3/88 (1819-1830): 208 v.- 232 v.; Inventarios generales, 2-57-6 (1840): 11 v.; 1-14-4 (1855): 3 v.; 5-329-5 (1897): 23 v. Pardo, 1951: 116. Reyero, 2010: 42.

53 ARASF, 7-130-1, Desamortizaciones (1835-1889), 6: 3-4; Comisión Especial de Formación de Inventarios de los Conventos Suprimidos. Correspondencia (1835-1836), 7-128-1: 4 y 15. AGP, Exp. 16864/39: 10. Pardo, 1951 : 114. Calvo Martín, 2008: 232-233.

54 Madrid, 1996: 84-85.

55 Pardo, 1955: 110.

56 Pardo, 1951: 115.

57 ARASF, Actas, 3-104 (1900-1903): 75. Pardo, 1951: 119. Gómez, 1993: 143. Díez, 1997: 44-45.

58 Pardo, 1951: 113-115. Cerrillo, 2005: 135-139. Ramírez, 2011: 151-152.

59 Reyero, 2003.

${ }^{60}$ AGP, Exp. 16864/39, expediente 16. Pardo, 1951: 116. Melendreras, 1987: 1697-1698. Mazón, 2001: 139-140. Álvarez, 2003: 531. Cerrillo, 2005: 137. Azcue, 2012a: 346.
} 
- Decoración escultórica de la fachada del Real Museo, actual Museo del Prado (1830). La intervención de Elías en esta fachada ya fue descrita por Pardo Canalís y ha sido dada a conocer por Azcue ${ }^{61}$. Fue involucrado en este proyecto hacia 1830, encargándosele la talla de una escultura de Apolo iniciada por Pedro Hermoso. Con sus nombramientos de Segundo y Primer Escultor de Cámara fue adquiriendo más responsabilidad en el proyecto, pero no parece que llegara a involucrarse a fondo en él. La escultura de Apolo estuvo diez años en el taller del Escultor de Cámara sin avances significativos, mientras Elías se dedicaba a otras obras, como las que "tenía entre manos para la Plazuela de Oriente" 62 , hasta que devolvió la piedra sin acabar al Museo. Francisco también colaboró en la talla de diversas alegorías de Virtudes, iniciadas por Salvatierra, para las hornacinas de la fachada principal; Carrasco ha apuntado que las imágenes de la Victoria y la Fama, por su estilo, podrían atribuirse a Elías $^{63}$. Por último, sí que realizó, en 1833, al tener lugar la jura de Isabel II como Princesa Heredera, varias esculturas efímeras, en escayola, destinadas a dar un mejor aspecto a la inconclusa fachada. Estaban destinadas a los extremos del frontón y representaban a España, junto a un león y un escudo de armas, y a América, con un caimán a sus pies, así como un grupo de la Fama y un Escudo de España para el remate de la fachada ${ }^{64}$. A pesar de su carácter efímero, estas imágenes tardaron años en ser retiradas por el lento ritmo de las obras de la fachada.

- Esfinges de la Exedra del parque de El Capricho de la Alameda de Osuna: en 1834, junto a José Tomás, Elías trabajó en la decoración escultórica del Capricho de la Alameda de Osuna. $\mathrm{Su}$ trabajo fue realizar seis esfinges, en plomo fundido, tres de estilo clásico y tres de estilo egipcio, que rodean el conjunto apoyadas en pedestales ${ }^{65}$.

- Constancia para el Monumento a las Víctimas del Dos de Mayo en la plaza de la Lealtad de Madrid (1843). La Constancia era una de las cuatro imágenes alegóricas colocadas en los lados del obelisco principal, ejecutada según modelo de Esteban de Ágreda. Elías debía de sentirse orgulloso de esta escultura, ya que aparece en el retrato que le hizo Zacarías González Velázquez y que ya hemos comentado. Domínguez le atribuyó el León del bajorrelieve inferior, aunque es obra de José Tomás ${ }^{66}$.

- Decoración del pedestal de la escultura ecuestre de Felipe IV en la Plaza de Oriente (1844): para este pedestal, Elías realizó uno de los bajorrelieves alusivo a Felipe IV, Felipe IV concediendo a Diego de Velázquez el hábito de la Orden de Santiago, una escultura que representaba al Río Manzanares, situada enfrente del Teatro Real y cuatro esculturas representando Leones ${ }^{67}$. Su compañero en esta obra fue nuevamente José Tomás.

- Alegoría de la Beneficencia, para el Teatro del Instituto (1845): la decoración interior y exterior de este teatro había sido realizada, entre otros, por Francisco Elías Burgos, pero las dos esculturas de mayor entidad fueron encargadas a su padre, Elías Vallejo (la Beneficencia) y a José

61 Pardo, 1951: 116. Azcue, 2012b: 98-126.

62 Pardo, 1951: 294.

63 Carrasco, 1999:123.

${ }^{64}$ Pardo, 1951: 116, 249, 293-294. Mazón, 2001: 139-140. Sánchez, 2011: 120. Azcue, 2012b:102. Además, se instalaron dos de las esculturas de Reyes españoles destinadas al Palacio Real, que fueron restauradas Elías y Tomás.

${ }^{65}$ Navascués, 1975: 21. Azcue, 2012a: 346.

${ }_{66}$ Madrazo, Pedro, "Su estado actual en la capital de España. Escultura. Estatuaria". En: El Laberinto, 15-71844: 246. Sala, 1862: 367. Caveda, 1867: 263-264. Ossorio, 1883: 184-185. Domínguez, 1903: 100. Rincón, 1909: 295. Pardo, 1951: 116-117. Rincón, 1991: 9, 11, 12 y III. Gómez, 1993: 53. Ramírez, 1998: 37. Reyero, 1999b: 503. Arias, 1999: 80. Reyero, 2003: 44. Álvarez, 2003: 531. Cerrillo, 2005: 137. Ramírez, 2011: 152. Azcue, 2012a: 346.

${ }^{67}$ Madrazo, Pedro, "Su estado actual en la capital de España. Escultura. Estatuaria". En: El Laberinto, Madrid, 15-7-1844: 246. Sala, 1862: 367. Caveda, 1867: 263-264. Pardo, 1951: 117. Pardo, 1966: 59-60. Gómez, $1993: 55$. Ramírez, 1998: 37. Arias, 1999: 80. Reyero, 2003: 43-44. Álvarez, 2003: 531. Cerrillo, 2005: 137. Ramírez, 2011 : 152. Azcue, 2012a: 346. 
Tomás (la Ilustración). Esta obra no se conserva porque el conjunto de edificios se derribó en $1897^{68}$.

- Retratos fundidos en la Fábrica de Trubia: entre 1846 y 1856, Elías realizó varios moldes de retratos de personajes ilustres que fueron fundidos en hierro o bronce en la Fábrica de Trubia (Asturias) y, en su mayoría, destinados al antiguo Museo de Artillería. El listado de estos retratos es el siguiente:

Isabel II: este retrato de juventud de la reina se considera el primer busto fundido por la Fábrica de Trubia. Se realizaron de él 5 copias: una destinada a la Exposición Universal de Londres, otra al Parque de Artillería de Madrid (que hoy en día se conserva en el Museo del Ejército) y tres que quedaron en la fábrica. Es posible que una de ellas sea la que se colocó en un pedestal en la Universidad de Oviedo y que posteriormente se trasladó al Hotel Reconquista de esta misma ciudad, donde se encuentra hoy en día. Hay que indicar que Suárez opina que el busto podría ser obra de Francisco Pérez del Valle, más que de Elías ${ }^{69}$.

María Cristina de Borbón: este retrato es uno de los que más problemas presenta de atribución. Carrasco no lo cita y Suárez no cita ningún autor, limitándose a decir que se hicieron tres copias, de las que una se remitió al parque de Artillería y dos quedaron en la Fábrica de Trubia. Pardo Canalís identificó ese retrato con un busto de María Cristina que se conserva en el Senado, y que anteriormente había estado atribuido a Gragera. Sin embargo, Reyero ha planteado dudas sobre la atribución ya que, para él, el estilo de la imagen se adecúa más al de José Piquer, a quien él la atribuye ${ }^{70}$.

El Infante Luis yacente, primogénito de Isabel II, muerto el día de su nacimiento (12-71848), realizada en hierro. Sobre esta imagen hay menos dudas de atribución, ya que es citada por Canalís, Carrasco y Suárez, quienes la fechan en 1856. Según Suárez, el ejemplar del Museo del Ejército desapareció a mediados del siglo XX y solo existe un ejemplar en la biblioteca de la Fábrica de Trubia ${ }^{71}$.

Daoíz y Velarde: según Canalís serían dos retratos en hierro bronceado, fundidos en Trubia de 1846 a 1850. Carrasco los atribuye a Elías, mientras que Suárez no cita ningún autor, indicando que solo existe una copia en la fábrica. Esa indicación parece indicar que, finalmente, no se enviaron al Museo del Ejército. En ese caso, es probable que se puedan identificar con los que hoy se conservan en el depósito del Museo de Oviedo y que se atribuyen precisamente a Elías ${ }^{72}$.

Joaquín de la Pezuela, marqués de Viluma: según Pardo Canalís, el busto, en hierro, es idéntico a otro realizado en mármol y conservado en la colección personal del Marqués de la Pezuela. Suárez indica que fue destinado al Museo de Artillería de Madrid ${ }^{73}$.

Agustín de Argüelles: este busto se realizó hacia 1850, en hierro fundido. Carrasco lo atribuía a Elías y Suárez indicaba que de él se hicieron tres copias: dos para el Museo de Artillería y otra conservada en la Fábrica. Hoy en día, uno de los bustos se encuentra en el

68 "Miscelánea". En: Semanario pintoresco español, 12-10-1845: 360. Pardo, 1951: 117; 1952: 378-379. Ramírez, 1998: 37. Cerrillo, 2005: 137. Ramírez, 2011: 152.

${ }^{69}$ Carrasco, 1893: 83. Pardo, 1951: 118. Suárez, 1993: 160 y 191-192. Portela, 1997: 122. Álvarez, 2003: 531. Quijada Espina/Vázquez-Canónico, 2004: 56-57. Cerrillo, 2005: 137. Rodríguez, 2010: 52.

70 Avilés, 1917: n. ${ }^{\circ}$ 134. Pardo, 1951: 118 y fig. 74. Suárez, 1993: 160. Reyero, 1999a: 458. Álvarez, 2003: 531. Cerrillo, 2005: 137. Azcue, 2012a: 346.

71 Pardo, 1951: 118. Carrasco, 1893: 77. Suárez, 1993: 212-213. Gómez, 1993: 55. Cerrillo, 2005: 137. Azcue, 2012a: 346

72 Carrasco, 1893: 70-72. Pardo, 1951: 118. Suárez, 1993: 160. Álvarez, 2003: 531. Azcue, 2012a: 346. "Inventario de bienes del Patrimonio Municipal". En: <http:/www.oviedo.es/documents/12103/e4408566-e8ba-48f6-9ed6e805b685fc73> [03-11-2015]

73 Pardo, 1951: 118 y fig. 73. Suárez, 1993: 161. Portela, 1997: 121-122. Álvarez, 2003: 531. Álvarez, 2003: 531. Cerrillo, 2005: 136. Azcue, 2012a: 346. 
Congreso de los Diputados. También se conserva una copia en Asturias, en concreto en el Palacio Prieto Cutre de Ribadesella ${ }^{74}$.

Jovellanos: busto en hierro fundido. Carrasco lo fecha en 1850 y lo atribuye a Elías, indicando además que tomó como modelo el busto existente en el Instituto de Gijón. Suárez habla de dos bustos diferentes: uno que existe en esta fábrica y otro del que se hicieron tres copias: 2 para el Museo de Artillería y otro en la Fábrica. Por su parte, Arias hace referencia a este busto indicando que hoy en día se conserva en una colección particular ${ }^{75}$.

- Talía, musa de la Comedia, y Dos deidades mitológicas para el Teatro Real (1850): estas imágenes no se han conservado hasta nuestros días. De la que más datos tenemos es de la imagen de Talía, colocada inicialmente en el interior del Teatro Real. Hacia 1862 fue trasladada al exterior, siendo colocada sobre un pedestal en la Plaza del Teatro. Sin embargo, hacia 1865 se retiró nuevamente para colocar una escultura de Isabel II, por lo que acabó por ser desechada ${ }^{76}$.

Además de estas obras, Elías realizó en ocasiones labores de restauración o mejora de obras ya construidas. Estas labores fueron especialmente frecuentes en sus años como Ayudante de Escultor de Cámara, pero se prolongaron durante toda su vida. Tenemos conocimiento de los siguientes encargos:

- Restauración de la Fuente de Neptuno en el Paseo del Prado en Madrid (1825-1830), dañada durante la Guerra de la Independencia ${ }^{77}$.

- Restauración de las fuentes de Hércules y Anteo, Apolo, Cisne y Ceres en Aranjuez (18251830). Conservamos las solicitudes para trasladarse a Aranjuez a cumplir con estos encargos, pero solo sabemos en qué consistió la intervención de Elías en el caso de la fuente de Hércules y Anteo, situada en el Jardín del Parterre de Aranjuez, y que justamente había sido construida por su maestro, Juan Adán. Allí realizó diversas reparaciones y ejecutó una imagen de Hércules niño luchando contra una serpiente ${ }^{78}$.

- Restauración de la Fuente de las Cadenas, en Aranjuez: sabemos que Elías intervino en esta fuente hacia 1836, probablemente dentro de las intervenciones que tuvieron lugar en esta fuente en los años 30, enriqueciendo el conjunto con elementos decorativos como lagartos, caracolas, soles o amorcillos cabalgando sobre tritones ${ }^{79}$.

- Restauración de la imagen de Josías del Patio de los Reyes de El Escorial (1856). Este encargo, más tardío, consistió en reponer la cabeza de este rey judío, que había sido destruida por un rayo ${ }^{80}$.

Por último, otra parte significativa del trabajo de Elías en encargos públicos fue la participación en monumentos de carácter efímero, realizados en materiales perecederos, destinados a decorar Madrid con motivo de acontecimientos importantes. Conocemos la lista de las obras en las que participó, aunque ninguna de ellas haya llegado hasta nuestros días:

- El Tiempo entre la Fidelidad y el Amor conyugal rompiendo los lazos de Himeneo, realizado con motivo del fallecimiento de la reina María Isabel de Braganza en 1819 para el monumen-

74 Carrasco, 1893: 75-76. Pardo, 1951: 118. Suárez, 1993: 161 y 200-201. Arias, 1999: 80. Álvarez, 2003: 531. Cerrillo, 2005: 136. Azcue, 2012a: 346.

75 Carrasco, 1893: 74. Suárez, 1993: 160-161. Arias, 1999: 80. Álvarez, 2003: 531.

76 Sala, 1862: 367. Caveda, 1867: 263-264. Domínguez, 1903: 107. Pardo, 1951: 118 85. Pardo Canalís, 1951: 116. Ramírez, 1998: 38. Álvarez, 2003: 531. Ramírez, 2011: 152.

77 Domínguez, 1903: 100. Ramírez, 1998: 37. Ramírez, 2011: 152.

78 AGP, Exp. 16864/39, expediente 14, 18, 19 y 23. Sala, 1862: 367. Ossorio, 1883: 114 y 116. Rincón, 1909: 295. Pardo, 1951: 116. Ramírez, 1998: 37. Arias, 1999: 80. Cerrillo, 2005: 136. Ramírez, 2011: 152.

79 AGP, Francisco Elías Vallejo, exp. 16864/39, expediente 2 y 7. Luengo Añón, 2008: 314.

${ }^{80}$ Pardo, 1951: 118. Ossorio, 1883: 118. Rincón, 1909: 295. Ramírez, 1998: 37. Ramírez, 2011: 152. 
to funerario de la iglesia de san Francisco el Grande. El grupo se volvió a utilizar en 1829 con motivo del fallecimiento de la reina María Josefa Amalia de Sajonia ${ }^{81}$.

- La Reina en actitud suplicante conducida entre nubes al cielo, en medio de la Esperanza y la Caridad, realizada en 1829 por el fallecimiento de la reina María Josefa Amalia y destinado también a la iglesia de san Francisco el Grande ${ }^{82}$.

- Hernán Cortés sosteniendo en su mano la bandera española, realizado en 1829 por el matrimonio de Fernando VII con María Cristina de Borbón y destinado a un templete colocado en la Puerta del Sol ${ }^{83}$.

- Bustos de Fernando VII y María Cristina, bajo un dosel y una corona imperial, y a sus pies tres genios que les presentaban los atributos propios de la Imprenta, realizado en 1830 con motivo del nacimiento de Isabel II y destinado al balcón de la Imprenta Real ${ }^{84}$.

- Minerva al serle presentada la recién nacida Princesa Isabel, realizado también con motivo del nacimiento de Isabel II en 1830 y destinado en esta ocasión a la decoración de un Carro triunfal en el que también trabajaron otros escultores académicos ${ }^{85}$.

- La augusta Princesa sentada en un trono, en actitud de admitir la corona y el cetro de las Españas, ofrecidos por Minerva, realizado en 1843 con motivo de la entronización de Isabel II nuevamente para la Imprenta Real ${ }^{86}$.

Además de estas imágenes, Ossorio añade que Elías realizó "varios caballos de madera para la Real Armería"87, de los que no tenemos más datos. Igualmente, Pardo asegura que durante el Trienio Laboral Elías trabajó en el Salón de Cortes, sin que sepamos qué obra realizó allí ni si tenía un carácter permanente o efímero ${ }^{88}$.

\section{Otros trabajos}

Además de su carrera en la Academia y en la Corte, Elías desempeñó otros trabajos y encargos. Hacia 1815, mientras esperaba que surgiera una vacante en la Real Academia de San Fernando, Elías entró a trabajar como artífice en la prestigiosa Fábrica Platería Martínez de Madrid $^{89}$. Posteriormente, pasó a ser profesor y director de la Escuela de Dibujo y modelado de esta institución, dando formación a los aprendices de la misma ${ }^{90}$.

En cuanto a encargos particulares, algunos se refieren a labores puntuales: sabemos, por ejemplo, que en 1831 el Duque de Frías le pidió que se trasladara a Burgos a tomar apuntes de la Capilla de los Condestables de Castilla ${ }^{91}$.

Sin embargo, la mayoría fueron encargos escultóricos y, la mayor parte, de tema religioso. Podemos citar los siguientes:

81 Pardo, 1949: 161-168. Prados, 1991: 87-95. Ramírez, 1998: 37. Álvarez, 2003: 531. Cerrillo, 2005: 136-137. Ramírez, 2011: 152.

82 ARASF, Noticias necrológicas y biográficas, 1-47-1 (siglo XVIII): s/f. Pardo, 1951: 116. Ossorio, 1883: 184185. Ramírez, 1998: 37. Arias, 1999: 80. Álvarez, 2003: 531. Cerrillo, 2005: 137. Ramírez, 2011: 152.

83 "Ornatos y fiestas de Madrid en la entrada de la Reina nuestra Señora". En: Mercurio de España, Madrid, $12-$ 1829: 444. Ossorio, 1883: 184. Pardo, 1951: 116. Ramírez, 1998: 37. Arias, 1999: 81. Mazón, 2001: 139-140. Cerrillo, 2005: 137. Ramírez, 2011: 152.

84 Ossorio, 1883: 184-185. Ramírez, 1998: 37. Arias, 1999: 81. Mazón, 2001: 139-140.

85 Ossorio, 1883: 184-185. Pardo, 1951: 116. Ramírez, 1998: 37. Arias, 1999: 80. Mazón, 2001: 139-140. Cerrillo, 2005: 137. Ramírez, 2011: 152.

86 Ossorio, 1883: 137. Arias, 1999: 81. Ramírez, 2011: 152.

87 Ossorio, 1883: 185. Ramírez, 1998: 37. Ramírez, 2011: 152.

${ }^{88}$ Pardo, 1951: 116

89 Martín, 2011: 95.

90 "Efeméride histórica". En: Diario oficial de avisos de Madrid, Madrid, 04-10-1884: 3. Domínguez, 1903: 66.

91 AGP, Exp. 16864/39, expediente 15. 
-San Blas: se trata de una talla religiosa que, según Domínguez, fue encargada por la cofradía del mismo nombre para la parroquia de San Esteban Protomártir de su localidad natal. Domínguez añadía que se podían atribuir también a Elías otras tres esculturas, que representaban a San Isidro y dos Angeles orantes, "aunque no tengamos pruebas para afirmarlo"92. Pardo Canalís recogió la noticia de Domínguez sin matizarla y señaló a Elías como autor de las cuatro imágenes, atribución que después han seguido el resto de autores ${ }^{93}$.

-Virgen del Socorro: en el Oratorio de Caballero de Gracia de Madrid se encuentra esta imagen, realizada en 1825 y cuya autoría está documentada. Tormo, que desconocía a su autor, sugirió que el grupo "tan lindo, es muy similar, si no igual a los de Salzillo", por lo que fue considerada de escuela salzillesca hasta las publicaciones de Gómez Moreno y Roscales. Desconocemos si ésta es la "Virgen con Niño" que, según Pardo Canalís, Elías presentó a "las exposiciones públicas de 1837, 1838, 1846 y otras"

- Altar de San Diego en Alcalá de Henares, construido bajo la dirección del arquitecto Isidro González Velázquez. Consta, de hecho, que Elías fue el responsable de colocarlo en su lugar en el templo ${ }^{95}$.

- Cristo Crucificado: Ossorio y Pardo lo citan, pero no tenemos ningún dato ni sabemos si se realizó para algún templo o convento ${ }^{96}$.

- Virgen Dolorosa: se encontraba en el Altar de la Misericordia de la parroquia de San Pedro de Gijón, donde fue entronizada en 1839. Fue destruida durante la Guerra Civil española ${ }^{97}$.

A estos encargos de tema religioso se pueden añadir otros encargos particulares. Probablemente, el más destacado sea el Busto de Jovellanos realizado para su enterramiento en la iglesia de San Pedro de Gijón, construido por Juan Miguel Inclán Valdés hacia 1842. Tras la Guerra Civil Española, el monumento se trasladó a la Capilla de los Remedios de Gijón ${ }^{98}$.

Otra obra fue una imagen de Cibeles, imitando a la madrileña, realizada en madera bronceada para su localidad natal, Soto en Cameros. Esta imagen, al ser hecha en madera, fue sufriendo pronto un gran deterioro hasta que fue definitivamente retirada $\mathrm{a}^{99}$.

Por último, podemos añadir a esta lista algunas obras atribuidas a Elías pero cuya autoría presenta ciertos problemas. Sala cita como obra suya una Santa Teresa a la que ningún otro autor hace referencia ${ }^{100}$. Navascués le atribuye un retrato de Custodio Moreno, que tampoco es recogido por otros autores ${ }^{101}$. En este caso, pensamos que podría tratarse de una confusión con Esteban de Ágreda, quien sí realizó un busto de Custodio Moreno ${ }^{102}$ y a quien a veces se confunde con Elías por ser ambos riojanos y directores de la Academia. Burgos cita a Francisco como autor de la escultura de Juan Esteban de Elías en Soto en Cameros, una autoría de la que, por el momento, no hemos encontrado refrendo en otras publicaciones ${ }^{103}$. Y otro caso es el relieve de San Miguel combatiendo a Luzbel para la capilla de San Miguel de la Catedral de Granada, que según Ramírez debía hacer Juan Adán pero éste "comisionó a Francisco Elías Vallejo para que acudiera a Granada y lo hiciera". Sin embargo, la autoría de Adán está refrendada por las publi-

92 Domínguez, 1903: 73-74 y 115. Ramírez, 2011: 153.

93 Pardo, 1951: 118. Ramírez, 1998: 38. Mazón, 2001: 139-140. Álvarez, 2003: 531-532. Cerrillo, 2005: 138. Ramírez, 2011: 153.

94 Ossorio, 1883: 185. Pardo, 1951: 118. Tormo, 1985: 149. Gómez, 1993: 56. Ramírez, 1998: 37. Cerrillo, 2005 : 137. Ramírez, 2011: 152. Roscales, 2014: 169-170.

95 AGP, Exp. 16864/39, expediente 22.

96 Ossorio, 1883: 185. Pardo, 1951: 118. Ramírez, 1998: 37. Ramírez, 2011: 152.

97 Sala, 1862: 367. "Esculturas españolas del tesoro artístico de Gijón". En: $A B C$, 05-04-1936: 146.

98 Ossorio, 1883: 184-185. Robles, 1936: 112. Pardo, 1951: 117-118. Gómez, 1993: 55. Azcue, 1994: 351-353. Ramírez, 1998: 37. Arias, 1999: 80. Álvarez, 2003: 531. Coronas, 2008: 277.

99 Domínguez, 1903: 73 y 115-116. Pardo, 1951: 118. Ramírez, 1998: 38. Mazón, 2001: 139-140. Álvarez, 2003: 531. Cerrillo, 2005: 138. Ramírez, 2011: 152-153.

100 Sala, 1862: 367

101 Navascués, 1993: 141.

102 Pardo, 1952b: 254.

103 Burgos, 2000: 85. 
caciones dedicadas a él. Pensamos que el encargo de Elías sería más bien colocar este relieve en su lugar correspondiente, tarea que, efectivamente, "tenía que hacerse obligatoriamente en la misma catedral" 104 .

En cualquier caso, estas obras quedan pendientes de un estudio más profundo que desmienta o confirme esta autoría.

\section{Conclusión}

La figura de Francisco Elías Vallejo se sitúa en la transición entre la tradición ilustrada y la romántica. Su actividad estuvo ligada a instituciones ilustradas, como la Academia de Bellas Artes o los encargos cortesanos de los Borbones, pero también participó en el primer desarrollo de la escultura pública, de tema heroico e historicista.

Este trabajo completa ciertos datos desconocidos o equivocados sobre sus orígenes familiares, su juventud y su formación artística, ofreciendo incluso el nombre de su primer maestro, Bernabé Romero. Sintetiza las aportaciones de las publicaciones existentes sobre él hasta nuestros días y recoge las obras que fue realizando tanto en el ámbito académico, como en el cortesano, como en cuanto a los encargos particulares.

Esperamos que este estudio pueda servir de base para otros trabajos que profundicen en las obras que realizó, sobre todo en los aspectos más desconocidos, como la escultura religiosa o los retratos. Asimismo, se hace necesaria una definición de su estilo que permita confirmar o rechazar las atribuciones de obras que se le han adjudicado. Todos estos aspectos resultarían muy útiles para seguir definiendo el puesto que Elías debe ocupar en la Historia del Arte español.

\section{BIBLIOGRAFÍA}

Agulló y Cobo, Mercedes (2005): Documentos para la historia de la escultura española. Madrid: Fundación de Apoyo a la Historia del Arte Hispánico.

Álvarez, Miguel (2003): Memoria monumental de Madrid. Madrid: Ediciones La Librería.

Araujo Sánchez, Ceferino (2005): Goya y su época: las artes al principiar el siglo XIX. Santander: Universidad de Cantabria.

Arias Anglés, Enrique (coord.) (1999): Historia del arte español: Del neoclasicismo al impresionismo. Madrid: Akal.

Avilés, Ángel (1917): Catálogo de las obras de arte existentes en el Palacio del Senado. Madrid: Fortanet.

Azcue Brea, Leticia (1994): La escultura en la Real Academia de Bellas Artes de San Fernando (catálogo y estudio). Madrid: Real Academia de Bellas Artes de San Fernando.

Azcue Brea, Leticia (2012a): "La escultura española durante el romanticismo: continuidad y cambios". En: Calvo Serra1ler, Francisco (dir.): El arte de la era romántica. Madrid: Fundación Amigos Museo del Prado.

Azcue Brea, Leticia (2012b): "El ornato exterior del Museo del Prado. Un programa escultórico inacabado". En: Boletín del Museo del Prado, 30, 48, Madrid, pp. 98-126.

Ballesteros Robles, Luis (1912): Diccionario biográfico matritense. Madrid: Ayuntamiento de Madrid.

Barcia, Ángel (1901): Catálogo de los retratos de personajes españoles que se conservan en la sección de estampas y de Bellas Artes de la Biblioteca Nacional, Madrid: Establecimiento tipográfico de la Viuda e hijos de M. Tello.

Burgos Esteban, Francisco Marcos (2000): La Rioja, tierra abierta. Logroño: Fundación Caja Rioja.

Calvo Martín, Rocío (2008): "La intervención de la Real Academia de San Fernando en la protección del patrimonio: la Comisión de Valentín Carderera (1836)”. En: Espacio Tiempo y Forma. Serie VII, Historia del Arte, 20-21, Madrid, pp. 229-266.

Calvo Torre, Roberto (2008): “El Camero Viejo, cuna de hijos ilustres”. En: Belezos: Revista de cultura popular y tradiciones de La Rioja, 7, Logroño, pp. 67-73.

Carrasco Ferrer, Marta (1999): "Las personificaciones esculpidas que adornan la fachada principal del Museo del Prado". En: Boletín del Museo del Prado, 35, Madrid, pp. 109-124.

Carrasco y Sayz, Adolfo (1893): Catálogo de los recuerdos históricos existentes en el Museo de Artillería. Madrid: Cuerpo de Artillería.

104 Ramírez, 2011:151. 
Caveda, José (1867): Memorias para la historia de la Real Academia de San Fernando y de las bellas artes en España, desde el advenimiento al trono de Felipe V hasta nuestros días. Madrid: Imprenta de M. Tello.

Cerrillo Rubio, María Lourdes (2005): "Escultura del siglo XIX”. En: Moya Valgañón, José Gabriel (dir.): Historia del Arte en La Rioja. Logroño: Fundación Caja Rioja, t. 5, pp. 125-144.

Coronas González, Santos M. (2008): Jovellanos y la Universidad. Oviedo: Fundación Foro Jovellanos del Principado de Asturias.

Díez, José Luis (1997): "La imagen del artista en la pintura española del siglo XIX”. En: Gállego, Julián (dir.): Artistas pintados. Retratos de pintores y escultores del siglo XIX en el Museo del Prado. Madrid: Ministerio de Educación y Ciencia.

Domínguez, Silverio (1903): Breves apuntes para la biografía de Francisco Elías Vallejo. Madrid: Imprenta Enrique Barea.

Espasa, José e hijos (1908): Enciclopedia universal ilustrada europeo-americana. Barcelona: José Espasa, t. 19.

Fernández García, Matías (1995): Parroquia madrileña de San Sebastián: algunos personajes de su archivo. Madrid: Caparrós.

Gómez Moreno, María Elena (1993): "Pintura y escultura del siglo XIX”. En: Pijoan, José: Summa Artis. Madrid: Espasa Calpe, t. XXXV*.

Lecuona, Manuel de (1954): "De la Guerra de la Independencia en La Rioja. Gacetillas. Extractos de cartas de la época. 1808-1809”. En: Berceo, 33, Logroño, pp. 449-462.

Luengo Añón, Ana (2008): Aranjuez, utopía y realidad: la construcción de un paisaje. Madrid: CSIC-Instituto de Estudios Madrileños y Ediciones Doce Calles.

Madrid Álvarez, Vidal de la (1996): "El Teatro Jovellanos de Gijón y el arquitecto Andrés Coello”. En: Boletín del Real Instituto de Estudios Asturianos, 148, Oviedo, pp. 84-85.

Martín, Fernando A. (coord.) (2011): El aragonés Antonio Martínez y su Fábrica de Platería en Madrid. Madrid: Museo de Historia.

Mazón Verdejo, Eugenio (coord.) (2001): Riojanos en Madrid: 601 biografias. Madrid: Centro Riojano de Madrid.

Melendreras Gimenos, José Luis (1987): "Monumentos murcianos del siglo XIX”. En: Estudios románicos, 6, Murcia, pp. 1697-1712.

Mellado, Francisco de Paula (1848): Diccionario Universal de Historia y Geografia. Madrid: Establecimiento topográfico Francisco de Paula Mellado, t. 6.

Navarrete, Esperanza (1999): La Academia de Bellas Artes de San Fernando y la pintura en la primera mitad del siglo XIX. Madrid: Fundación Universitaria Española.

Navascués Palacio, Pedro (1975): "La Alameda de Osuna: una villa suburbana". En: Pro-Arte, 2, Barcelona, pp. 6-26.

Navascués Palacio, Pedro (1993): “Arquitectura español. 1808-1914”. En Pijoan, José: Summa Artis. Madrid: Espasa Calpe, vol. $\mathrm{XXXV}^{* *}$.

Ossorio y Bernard, Manuel (1883): Galería biográfica de artistas españoles del siglo XIX. Madrid: Moreno y Rojas.

Pardo Canalís, Enrique (1949): “Cinco cenotafios reales de 1819 a 1834”. En: Arte Español, Madrid, pp. 161-168.

Pardo Canalís, Enrique (1951): Escultores del XIX. Madrid: Instituto Diego Velázquez-CSIC.

Pardo Canalís, Enrique (1952a): "Francisco Elías Burgos". En: Berceo, 24, Logroño, pp. 375-380.

Pardo Canalís, Enrique (1952b): “Acotaciones a un estudio sobre Esteban de Ágreda”. En: Archivo Español de Arte, 25, Madrid, pp. 249-256.

Pardo Canalís, Enrique (1955): "Escultores italianos de los siglos XVIII y XIX en España”. En: Archivo español de arte, 28, 110, Madrid, pp. 97-116.

Pardo Canalís, Enrique (1966): "El Jarama y el Manzanares en el Monumento a Felipe IV en Madrid". En: Goya, 73, Madrid, pp. 59-60.

Portela Sandoval, Francisco José (1997): “La Escultura y la Pintura en el Museo del Ejército”. En: Militaria. Revista de cultura militar, 9, Madrid, pp. 121-138.

Prados García, José María (1991): "Isidro González Velázquez y la arquitectura efímera". En: Cinco siglos de arte en Madrid (XV-XX). III Jornadas de Arte del Centro de Estudios Históricos del CSIC. Madrid: Alpuerto, pp. 87-95.

Quijada Espina, Ana/Vázquez-Canónico, Sara (coord.) (2004): Bienes culturales de la Universidad de Oviedo. Oviedo: Universidad de Oviedo.

Ramírez Martínez, José Manuel (1998): “El soteño Francisco Elías Vallejo, primer Escultor de Cámara y Director de la Academia de San Fernando". En: El Chapitel, 3, Logroño, pp. 36-38.

Ramírez Martínez, José Manuel (2011): "Elías Vallejo, Francisco". En: Diccionario Biográfico Español, 17, Madrid, pp. 151-153.

Reyero, Carlos (1999a): El arte en el Senado. Madrid: Secretaría General del Senado de España.

Reyero, Carlos (1999b): La escultura conmemorativa en España: la edad de oro del monumento público, 1820-1914. Madrid: Cátedra.

Reyero, Carlos (2003): "Monumentalizar la capital: la escultura conmemorativa en Madrid durante el siglo XIX". En: Lacarra Ducay, María del Carmen y Giménez Navarro, Cristina (coord.): Historia y política a través de la escultura pública. 1820-1920. Zaragoza: Institución Fernando el Católico, pp. 41-62.

Reyero, Carlos (2010): Alegoría, Nación y Libertad: el Olimpo Constitucional de 1812.Madrid: Siglo XXI.

Rincón García, Wifredo (1991): La escultura del siglo XIX. Madrid: Historia 16 - Cuadernos de Arte Español.

Rincón Lazcano, José (1909): Historia de los monumentos de la Villa de Madrid. Madrid: Imprenta municipal. 
Robles Muñiz, Emilio (1936): "Los bocetos del Instituto. El mausoleo de Jovellanos". En: Moratinos Otero, Orlando (ed.) (2006): Artículos de Emilio Robles Muñiz, Pachín de Melás, en el diario La Prensa (1928-1936). Oviedo: Fundación Foro Jovellanos del Principado de Asturias, pp. 110-115.

Rodríguez, Ramón (2010): "La revolución de 1934 y sus consecuencias en la Universidad de Oviedo". En: Boletín de la Fundación Emilio Barbón, III, Pola de Laviana, pp. 47-61.

Roscales Olea, Graciliano (2014): Historia artística del Real Oratorio del Caballero de Gracia. Madrid: Asociación Eucarística del Caballero de Gracia.

Sala, Juan (1862): Diccionario biográfico universal... desde los tiempos más remotos, hasta la época presente. Madrid: Gaspar y Roig.

Sánchez del Peral, Juan Ramón (2011): “Una grisalla de Francisco Martínez Salamanca para la decoración efímera del Museo del Prado con motivo de la jura de la infanta Isabel como princesa heredera". En: Boletín del Museo del Prado, 29, 47, Madrid, pp. 120-133.

Serrano Fatigati, Enrique (1912): Escultura en Madrid: desde mediados del siglo XVI hasta nuestros dias. Madrid: Hauser y Menet.

Suárez Menéndez, Roberto (1993): Fábrica de Trubia, 1794-1987: Historia y Producción artística. Candás: Centro de Escultura de Candás - Museo Antón.

Tormo, Elías (1985): Las iglesias de Madrid. Madrid: Instituto de España.

Fecha de recepción: 11-III-2016

Fecha de aceptación: 10-IX-2016 